\title{
Yield design modelling of dry-stone retaining walls
}

\author{
A. S. Colas ${ }^{1}$, J. C. Morel $^{1}$ \& D. Garnier ${ }^{2}$ \\ ${ }^{1}$ Département Génie Civil et Bâtiment (CNRS, URA 1652), \\ ENTPE, France \\ ${ }^{2}$ Laboratoire des Matériaux et des Structures du Génie Civil \\ (CNRS, UMR 113), ENPC, France
}

\begin{abstract}
Over the past few years, there has been a steady increase in the interest in dry-stone walling not only to preserve existing constructions but also to build new ones. Yet, no structural design method has been validated till today. In this study, a simplified model dedicated to dry-stone is propounded. This simulation, implemented in the rigorous framework of yield design homogenization, can meet engineering expectations. First, the model is introduced, and the parameter measurement detailed. Then, the validity of the method is assessed by comparisons with micro and macro-mechanical methods, and field trials. As a conclusion, possible improvements of the model are discussed.
\end{abstract}

Keywords: dry-stone, masonry, yield design, field trials.

\section{Introduction}

Dry-stone walling is a vernacular and widespread form of construction that can be found in many areas where there is a plentiful supply of raw materials. Drystone constructions rely on the skills of professional masons; they are built by fitting pieces of stone without mortar [1]. Throughout the industrial revolution a very large number of dry-stone edifices have been raised as retaining walls or rural constructions, but in the early 1900s dry masonry has largely been given up on behalf of modern techniques. Nowadays, a large number of these constructions continue to fulfill their mission, more than a century after construction. In France for instance, a study [2] from the Road Department has shown that dry-stone masonry represented $18 \%$ of the retaining walls along French main roads. On the 
other hand, over the past few years, there has been a far more new interest in dry-stone construction, not only for the maintenance and assessment of existing heritage, but also to promote know-how and complete new projects. Yet, it proved that there was a lack of scientific knowledge about dry-stone construction behaviour. Thus, in addition to dry-stone associations and masons promotional activities, scientific studies have been launched to simulate dry-stone walls.

Dry-stone buildings are extremely difficult to model given their random nature, and their stability is likely to depend on a lot of different factors such as material properties, block arrangement, or loading process. Nowadays, there is no structural design method to prevail against others. Actually, there have been only a few studies on dry construction design but two different approaches can be distinguished. Dry-stone walls can be assumed to behave as homogeneous rigid structures that yield to solid mechanics [3, 4]. Wall safety is actually checked by simple limit equilibrium analysis and qualitative visual examination. This approach fails to take into account the characteristics of dry-stone internal behaviour. A second way of simulating dry-stone walling consists in considering that it is made of distinct pieces of stone linked by contact laws. Dickens and Walker [5] pioneered this method using the distinct element code UDEC to model walls at Great Zimbabwe National Monument. Harkness et al. [6] have applied this technique to Burgoyne's field trials [7], and their study was expanded later on [8-10]. UDEC is based on the Distinct Element Method (DEM). This program happens to be a powerful device to simulate masonry behaviour under loading till failure and supplies indeed plentiful information on the wall properties. However, it proves quite complex and time-consuming, and thus does not fit yet for practical calculation of ultimate bearing capacities.

The Department of Civil Engineering and Building (DGCB) of ENTPE has been involved in the simulation of dry-stone masonry since 1998. A first PhD thesis by Boris Villemus [11] has been dedicated to better understanding internal failure within dry-stone retaining wall, based on macro-mechanics and field trials. These results are now been exploited to construct a rigorous but pragmatic simulation, resorting to yield design. The work presented here initiates the use of yield design homogenization to assess dry-stone wall stability. The simulation will first be presented, with special attention paid to the involved parameters. Then, the results obtained are compared with those found by a simple limit equilibrium analysis, distinct element method and field trials. As a conclusion, the future perspectives expanding on this work will be developed.

\section{Theoretical analysis}

The model presented in this work utilises yield design kinematic approach. Yield design provides the ultimate bearing capacity of a structure under a multiparameter loading, which is based upon the sole knowledge of the geometry, loading mode, and strength criterion of the constituent material. This method, based on the principle of virtual work, was first devoted to soil mechanics [12, 13], but recent works proved that it could be applied to various kinds of masonry [14- 
16]. The following section describes the procedure to model a dry-stone retaining wall using this method.

\subsection{Homogenization process}

Considering the difficulties induced by the heterogeneity of the masonry, it has been decided to simulate dry-stone masonry by a regular and periodic structure (Fig. 1(b)). This hypothesis enables to calculate the wall macroscopic yield criterion depending on the block and joint properties, by an homogenization method for periodic media [14]. The joints will be assumed to have a purely frictional Mohr-Coulomb criterion, only depending on the friction angle of the stones $\phi$ and the stones will be considered as infinitely resistant.

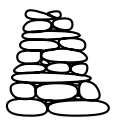

(a)

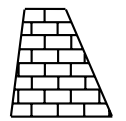

(b)

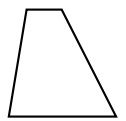

(c)

Figure 1: Modelling process.

\subsection{Yield design modelling}

The homogenization process described previously enables to undertake a macroscopic stability assessment of the wall, now considered as a homogenized continuous medium.

The system under investigation (Fig. 2) is a wall of height $h$, thickness at the top $l$, batter $\lambda_{1}$, and counter-slope $\lambda_{2}$, which yield criterion has been established above. This wall is subjected to its unit weight $\underline{\gamma}$, and to an external backfill pressure $\underline{p}_{b}$ on its back face, which distribution will be considered as linear.
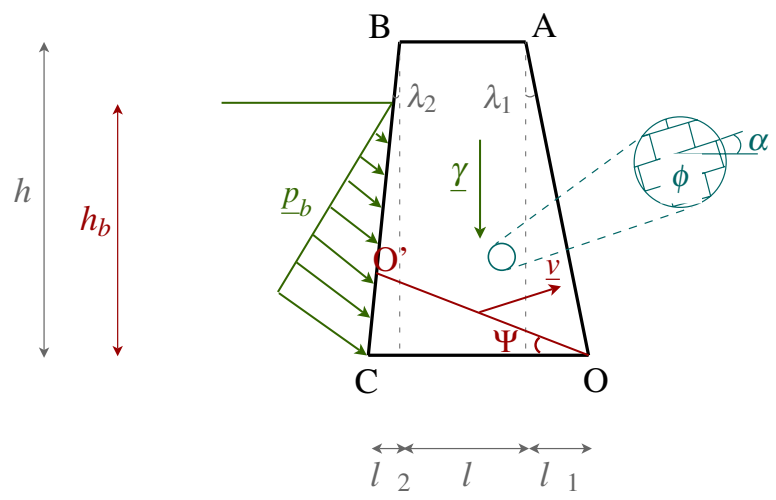

Figure 2: Studied system. 
Once these three types of parameters are determined, yield design approach can be undertaken. Since yield design relies on the principal of virtual work, we have to define virtual velocity field. The wall is intended to break from the toe of the wall $O$ along $O O^{\prime}$, which form an angle of $\Psi$ from horizontal. The lower part of the wall $O O^{\prime} C$ remains fixed whereas the trapezium $O A B O^{\prime}$ is given a velocity $\underline{v}$ :

$$
\underline{v}(\underline{X})=\underline{\chi}-\omega \underline{e}_{3} \wedge \underline{X}
$$

where $\chi$ is the velocity and $\omega(>0)$ the angular velocity of point $O$.

Then, the balance between the work of external forces $\mathscr{W}^{e}$ and the maximum resisting work $\mathscr{W}^{m r}$ is established:

$$
\mathscr{W}^{e}=p_{3}(\Psi, \underline{\chi}, \omega) h_{b}{ }^{3}+p_{2}(\Psi, \underline{\chi}, \omega) h_{b}{ }^{2}+p_{1}(\Psi, \underline{\chi}, \omega) h_{b}+p_{0}(\Psi, \underline{\chi}, \omega) \leq 0=\mathscr{W}^{m r}
$$

where $p_{i}$ are coefficients only depending on the kinematic parameters.

The critical value of backfill $h_{b}^{+}$can thus be written:

$$
h_{b}^{+}=\min _{\Psi, \underline{\chi}, \omega}\left\{h_{b 0}(\Psi, \underline{\chi}, \omega)\right\}
$$

where $h_{b 0}$ is the positive root of $\mathscr{W}^{e}$.

Yield design gives an indication on the failure characteristics. The velocity $\underline{v}$ provides the failure mode - sliding or overturning, and the failure plan inclination $\Psi$. Finally, $h_{b}^{+}$only depends on the three kinds of parameters described above:

$$
h_{b}^{+}[\underbrace{h, l, \lambda_{1}, \lambda_{2}}_{\text {geometry }}, \underbrace{\gamma, p_{b}}_{\text {loading }}, \underbrace{\phi, \alpha}_{\text {strength }}]
$$

Therefore, this method succeeds in taking into account the possible internal failure in the wall, and proves indeed easy to carry out, since requiring no programming and only few parameters.

\section{Parameter measurement}

Yield design stability assessment only involves geometric, loading and strength parameters.

The geometric parameters (height, thickness, batter, counter-slope) can be measured during the construction or repair of the wall.

Considering the loading process, there are only two parameters acting on the wall. The unit weight $\gamma$ of the wall depends on the unit weight of the stones as well as the void percentage in the wall. Experimental measurements by Villemus $[11,17]$ provides an average value of $25 \%$, which corresponds to empirical statements. The second force acting on the wall is due to the backfill pressure $\underline{p}_{b}$. Water pressure distribution is linear and normal to the back face of the wall (no friction between the wall and its backfill), but earth pressure is far more difficult to model, as it depends on the friction angle $\delta$ between the wall and the backfill, 
and on the earth pressure coefficient. It has been decided here to consider the distribution as linear, inclined from an angle $\delta=\phi_{s}$, the friction angle of the backfill, and proportional to Coulomb's earth pressure coefficient.

The strength criterion of the wall only depends on the inclination of bed joints and the friction angle $\phi$ between the stones. This angle can be measured thanks to shear tests on stone samples. In this study, Raffard's [18] and Villemus's [17] results have been used. New tests have also been performed to characterize limestone and granite friction angle.

\section{Numerical and experimental assessment of the model}

The validation of the model will now be undertaken, using both numerical and experimental tests.

\subsection{Numerical validation}

A way of evaluating the relevancy of the model consists in verifying its robustness towards other simulation processes. Therefore, a parametric analysis related to Burgoyne's field trials [7] will be conducted. In 1834, Lieutenant-General Sir John Burgoyne undertook full-scale tests on four dry-stone walls. Each wall was backfilled with uncompacted earth, made of granite, and of the same height and volume, but with different cross-sections. These tests aimed at evaluating the influence of geometry on their stability. Since they remain the most important fullscale trials in scientific history, many studies [6, 8-10] have been devoted to these experiments. However, the lack of information concerning physical characteristics of the backfill or even the wall has led us to concentrate on the numerical results, out of any experimental consideration.
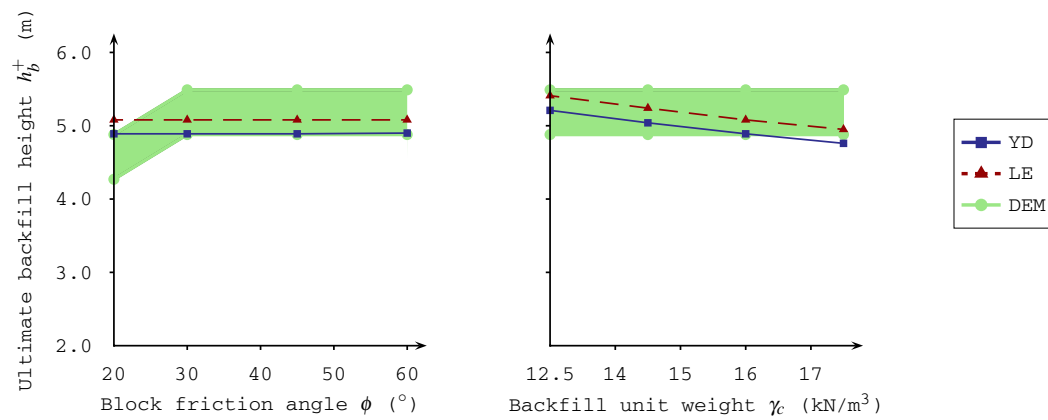

Figure 3: Dry-stone wall stability depending on block friction angle and backfill unit weight: yield design (YD), limit equilibrium (LE), and distinct element method (DEM) simulations. 
This work concentrates on the numerical study by Claxton et al. [10], which evaluates the sensitivity of Burgoyne's wall stability towards parametric variations using distinct element method (DEM). The same parametric tests as those of Claxton et al. were carried out on yield design model and limit equilibrium analysis (see Fig. 3). These tests aimed at investigating which properties could control stability, but also showing how the different models could behave.

First, it can be noted that the results provided by yield design are linear whereas DEM results are given as an interval. This is due to the choice of Claxton et al. to build the backfill by $30 \mathrm{~cm}$ high layers. Considering the first graph (Fig. 3(a)), it can be noted that yield design provides lower values than limit equilibrium, meaning that yield design is better for safety. Comparing yield design and DEM, the two models happen to be close. However, yield design fails to take into account the block friction angle influence. Besides, the effects of the unit weight of the backfill (Fig. 3(b)) only appear in yield design calculations - wall stability decreases with increasing soil density. Yield design model proves more sensitive to variations because it provides continuous solutions whereas DEM gives discrete numerical results. More precise computations could be achieved by diminishing fill layers in the discrete element simulation, at the expense of a longer calculation time.

This parametrical analysis shows the robustness of yield design towards other simulations: it is more accurate than limit equilibrium, and acts mainly in a similar manner with the distinct element method at failure.

\subsection{Experimental validation}

The main validation of the yield design model will be performed by comparing it to field trials. Numerical simulations were conducted on Villemus's field trials $[11,17]$ : Villemus has carried out experimental studies on five full-scale dry-stone walls built by skilled masons (Fig. 4).

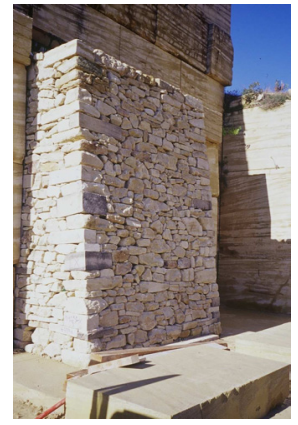

(a)

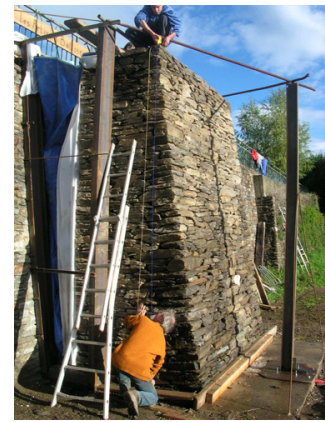

(b)

Figure 4: Villemus's experimental walls 3 (a) and 5 (b). 
Table 1: Geometrical characteristics of Villemus's walls [17].

\begin{tabular}{|l|c|c|c|c|c|}
\cline { 2 - 6 } \multicolumn{1}{c|}{} & Wall 1 & Wall 2 & Wall 3 & Wall 4 & Wall 5 \\
\hline Height $h(m)$ & 1.85 & 1.85 & 3.85 & 1.90 & 4.10 \\
\hline Thickness $l(m)$ & 0.60 & 0.90 & 1.20 & 0.65 & 1.16 \\
\hline Batter $f_{1}(\%)$ & 15 & 0 & 15 & 12 & 15 \\
\hline
\end{tabular}

Four were of limestone (walls 1-4), and one of schist (wall 5); the dimensions of each wall are given in table 1.

These walls have been loaded by water pressure until they collapsed, and the failure process has been recorded throughout the experimental study. Therefore, this work can be directly exploited to test the validity of yield design theory on dry-stone walls. The critical backfill heights of each wall have been calculated using yield design (YD) and compared to the actual failure height and mode (Ex.) which have occurred (see table 2).

Table 2: Experimental validation of the model on Villemus's field trials.

\begin{tabular}{|c|c|c|c|c|c|c|c|c|c|c|}
\hline & \multicolumn{2}{|c|}{ Wall 1} & \multicolumn{2}{|c|}{ Wall 2} & \multicolumn{2}{|c|}{ Wall 3} & \multicolumn{2}{|c|}{ Wall 4} & \multicolumn{2}{|c|}{ Wall 5} \\
\hline Type $^{\mathrm{a}}$ & $S$ & $\mathrm{O}$ & $S$ & o & $\mathrm{S}$ & o & $\mathrm{S}$ & o & $S$ & $\mathrm{O}$ \\
\hline $\mathrm{YD} h_{b}^{+}$ & 1.75 & 1.82 & 1.90 & 1.86 & 3.62 & 3.75 & 1.97 & 1.87 & 4.04 & 4.00 \\
\hline$(\Psi)$ & (0) & (16) & (0) & (17) & (0) & (16) & (0) & (16) & (0) & (17) \\
\hline $\begin{array}{r}\operatorname{Ex} . h_{b}^{+} \\
\quad(\Psi)\end{array}$ & $\begin{array}{r}1.59 \\
(u)^{\mathrm{b}}\end{array}$ & - & & & $\begin{array}{r}3.22 \\
(12)\end{array}$ & - & & 34 & $\begin{array}{r}3.48 \\
(9)\end{array}$ & - \\
\hline
\end{tabular}

${ }^{a}$ Failure process: $\mathrm{s}=$ sliding, $\mathrm{o}=$ overturning.

${ }^{b}$ The failure angle of the wall was not measured in the first two experiments.

Numerical tests have proved that yield design could simulate the failure mode and the ultimate water height. It slightly over-estimates the sliding ultimate height (error rate from 7 to $16 \%$ ) but accurately calculates the critical overturning height (error less than 6\%). This works enables the practical validation of this method as an effective tool to assess dry-stone wall stability.

\section{Conclusions}

Dry-stone masonry is a widely expanded form of construction, and an important heritage can be found all around the world. However, no structural design method has been validated until recently. Limit equilibrium analysis fails to consider 
internal failure within the wall, and distinct element method is too complex for practical determination of ultimate loads.

This study has presented a method to assess dry-stone wall stability under external pressure thanks to homogenization and yield design theory. This technique takes into account the heterogeneity of the structure while keeping a macroscopic approach, with only few parameters and no calculation time. Comparisons with models found in literature have shown the robustness of yield design modelling (more precise than limit equilibrium, accurate correspondence with DEM). On the other hand, experimental measurements have validated the use of this model on dry-stone walls under water pressure.

Further perspectives on this work are considered. First, improvements on the model will be undertaken by integrating the backfill into the studied system. This should enable the model to release from the backfill pressure distribution. Indeed, full-scale experiences on earth-retaining walls are planned, with the intent to validate the model with this kind of backfill. The final objective is to set up a criterion, which can be directly exploited for design and assessment of dry-stone walls.

\section{References}

[1] Lassure, C. \& Repérant, D., Cabanes en pierres sèches de France. Édisud: Aix-en-Provence, Édisud edition, 2004.

[2] Odent, N., Recensement des ouvrages de soutènement en bordure du réseau routier national. Ouvrage d'Art, (34), pp. 15-18, 2000.

[3] Arya, A. \& Gupta, V., Retaining walls for hill roads. Indian Roads Congres, 356, pp. 291-326, 1983.

[4] Cooper, M.R., Deflections and failure modes in dry-stone retaining walls. Ground Engineering, 19(8), pp. 40-45, 1986.

[5] Dickens, J.G. \& Walker, P., Use of distinct element model to simulate behaviour of dry-stone walls. Structural Engineering Review, 8(2/3), pp. 187-199, 1996.

[6] Harkness, R.M., Powrie, W., Zhang, X., Brady, K.C. \& O’Reilly, M.P., Numerical modelling of full-scale tests on drystone masonry retaining walls. Géotechnique, 50(2), pp. 165-179, 2000.

[7] Burgoyne, J., Revetments of retaining walls. Corps of Royal Engineering Papers, 3, pp. 154-159, 1853.

[8] Powrie, W., Harkness, R.M., Zhang, X. \& Bush, D.I., Deformation and failure modes of drystone retaining walls. Géotechnique, 52(6), pp. 435-446, 2002.

[9] Zhang, X., Koutsabeloulis, N.C., Hope, S. \& Pearce, A., A finite element analysis for the stability of drystone masonry retaining walls. Géotechnique, 54(1), pp. 57-60, 2004. 
[10] Claxton, M., Hart, R., McCombie, P.F. \& Walker, P., Rigid block distinctelement modeling of dry-stone retaining walls in plane strain. Journal of Geotechnical and Geoenvironmental Engineering, 131(3), pp. 381-389, 2005.

[11] Villemus, B., Étude des murs de soutènement en maçonnerie de pierres sèches. Ph.D. thesis, INSA Lyon, 2004.

[12] Salençon, J., Calcul à la rupture et analyse limite. Presses de l'École Nationale des Ponts et Chaussées: Paris, 1983.

[13] De Buhan, P., Approche fondamentale du calcul à la rupture des ouvrages en sols renforcés. Thèse d'État, Université Paris VI, 1986.

[14] De Buhan, P. \& De Felice, G., A homogenization approach to the ultimate strength of brick masonry. Journal of the Mechanics and Physics of Solids, 45(7), pp. 1085-1104, 1997.

[15] Corfdir, A., Analyse de la stabilité des ouvrages en gabions cellulaires par la théorie du calcul à la rupture. Thèse de doctorat, École Nationale des Ponts et Chaussées, 1997.

[16] Sab, K., Yield design of thin periodic plates by a homogenization technique and an application to masonry walls. C R Mecanique, 331, pp. 641-646, 2003.

[17] Villemus, B., Morel, J. \& Boutin, C., Experimental assessment of dry stone retaining wall stability on a rigid foundation. Engineering Structures. In press, Corrected Proof, Available online 18 December 2006.

[18] Raffard, D., Modélisation de structures maçonnées par homogénéisation numérique non linéaire: Application aux ouvrages d'intérêt archéologique. Ph.D. thesis, Institut National Polytechnique de Lorraine, 2000. 